\title{
57 A NEW APPROACH FOR E-LEARNING IN COLLABORATIVE NETWORKS
}

\author{
Dan Gârlaşu, Ioan Dumitrache, Aurelian Mihai Stanescu \\ Politehnica University Bucharest \\ 313, Splaiul Independentei, 060042 Bucharest, ROMANIA \\ \{dgarlasu@yahoo.com;dumi@ics.pub.ro;ams@cpru.pub.ro\}
}

\begin{abstract}
The paper proposes a new holistic model - the E-Learning Cube - with the aim to enable better understanding and characterization of the basic principles and mechanisms of E-Learning, for efficient use of the underlying infrastructure and a successful implementation strategy within Collaborative Networks. A short case study is presented in order to demonstrate how the new model was used for the implementation of an e-Learning system in a Collaborative Environment. Eventually the authors conclude with guidelines towards an ontology-based approach for e-Learning.
\end{abstract}

\section{INTRODUCTION}

Knowledge Economy (KE) refers to the new paradigm that has changed in the past fifteen years the functionality and economic rules at global level. The essence of these changes refer to the fact that ideas and knowledge become essential for the new economy as compared to the industrial model based on material resources. The key for the creation of new working places and the increase of the quality of life are the innovation and the technology embedded in services and products. As a consequence, the future belongs to the accumulation and execution based on knowledge. The Virtual Enterprise (VE) is the representation of the basic entity that operates in the knowledge economy. Knowledge is not only learning and information - these are in fact the raw materials of the new economy. Knowledge represents the added value of providing services and products. When converging, learning and technology enable individuals and teams to provide value for their customers and competitive advantage for the team or their organization. The discovery of new information is the key of the knowledge economy. Also, the desire to develop the self and the others - learnativity, is a term that states the dependence of the individual and organizational efficiency of a better, faster, more intelligent assimilation of information through a consistent application of instruction combined with creativity and flexibility (Hodgins, 2000). Also the Web enables people to build enduring communities of practice when they can come together to share knowledge and insight long after the training has taken place. This can be a tremendous motivator for organizational learning. Key for this process is the efficient absorption of information that makes possible the knowledge transfer within the appropriate 
time interval, to the right person, at the right moment and in a form suitable to what the receptor. When such a process takes place, the student can act promptly and efficiently. Traditional Instructor led training cannot scale to meet the new learning challenges. Or exactly here the authors see the role of E-learning - to provide the tools able to create, deliver and facilitate the training of the knowledge workers, anytime and anywhere.

\section{THE E-LEARNING CUBE MODEL}

There is much controversy around the e-Learning topic today. Be it from material (infrastructure reasons) or immaterial (lack of strategy, poor content, lack of interactivity and pedagogical skills, etc.) e-Learning did not succeed everywhere. That is the reason why the present paper introduces a new model, the E-Learning Cube, as a tool able to facilitate the understanding and faster identification of the root causes for various problems and ensure a successful implementation process (Figure 1).

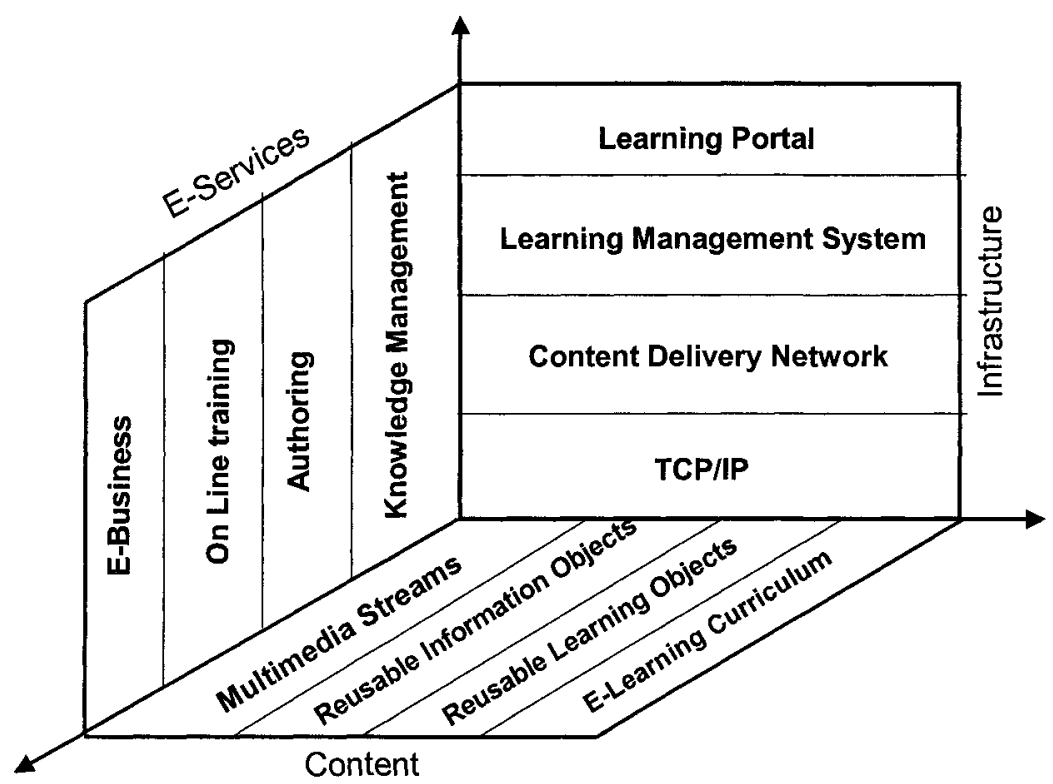

Figure 1 - E-Learning Cube

The available literature provides various one-dimensional models that capture part of the problem, be it about infrastructure or services (Dumke, 2003) or about the content involved during the knowledge transfer (IBM, 2001). Intuitively a multidimensional approach may represent better the complexity of the domain. Since a Cartesian frame provides orthogonal dimensions, independent views were searched in order to provide independent paradigms. The initial CIMOSA (ISO/TC 
184/SC 5) with its $4 \times 3 \times 3$ graphical representation provided a framework for information systems infrastructure (http://cimosa.cnt.pl/). This is in fact how the eLearning cube was evolved from the extended CIM-OSA, eCube' (Stanescu, 2002) with three dimensions (Infrastructure, Content and eServices) and their related components as described in the next paragraph.

\subsection{The Infrastructure Dimension}

The infrastructure - technological capabilities to deliver and manage E-learning - is key for a successful deployment. From the last mile access to the learning management system and the learning portal, lacking of a good infrastructure can jeopardize an e-Learning initiative. The goal however is to leverage on the mission and functions of a Collaborative Network (CN) as described in Figure 2.

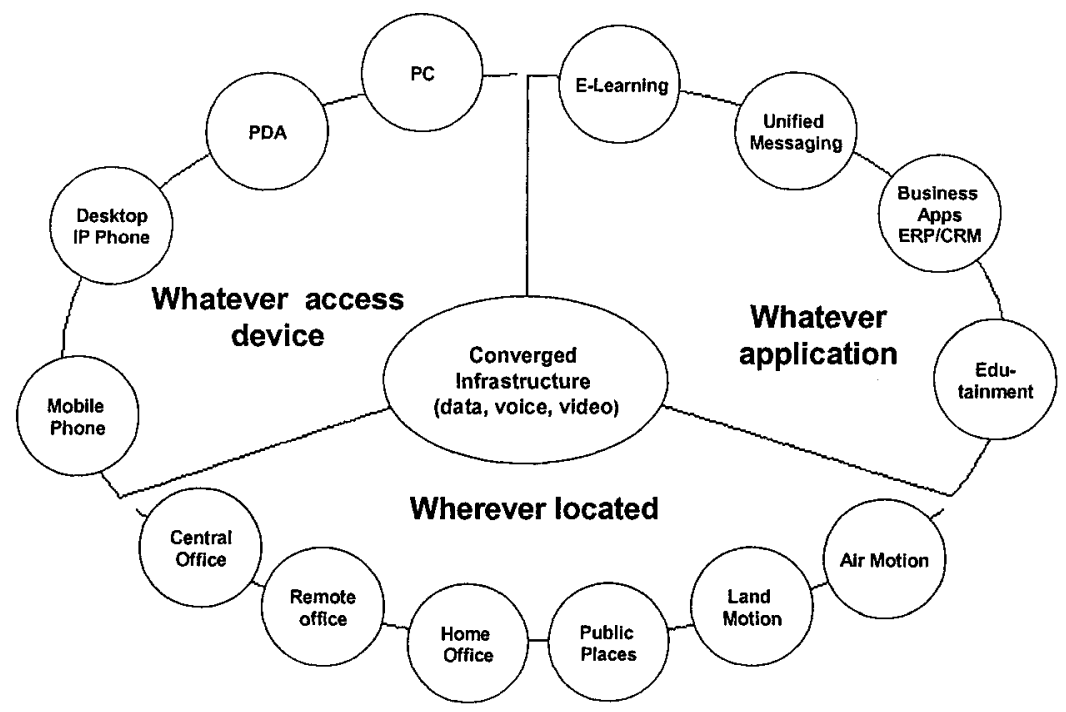

Figure 2 - Collaborative Networks Ubiquitous Access

A certain number of elements characterize the infrastructure dimension:

- TCI/IP is the underlying protocol for a communication infrastructure able to deliver real convergence of data, voice and video for scalable, secure and highly available applications. This objective is achieved through intelligent network services able to provide QoS (Quality of Service) for the constraints of the real time media streams, policing for differentiating between classes of services, network management, multicast, etc. The multimedia traffic dominant in eLearning applications may use multicast with predilection as it has different characteristics than HTTP or FTP traffic. A number of protocols have been developed that increase the efficiency of the Internet architecture and improve the support for audio, video and interactive multimedia conference streams. As a consequence multicast and real time multimedia flows are associated with 
protocols built on top of UDP such as RTP, RTCP, RSVP and RTSP. CORBA based middleware applications, enable implementation of mechanisms and services such as request-reply, naming, events notification, persistence, security, etc. independent of the underlying transport be it TCP or UDP (Coulouris 2001).

- Content Delivery Networks represent the infrastructure layer that enables content optimization. This layer provides mechanisms such as Web-browser TV used to broadcast live video to a big number of users at the same time, or VoD (Video on Demand) to allow the presentation of the content directly to the learner on demand, or Interactive multi-media that combines self-paced webbased training, online communities and instructor-led forums creating a complete way to transfer the knowledge and finally virtual class rooms that allows collaboration of geographically dispersed audience with interactive presentation capabilities, virtual hands-on labs, etc. Linking users with common interests to each other allows them to share views on the usefulness of information provided and to share experience and continuously enhance their knowledge thus building Communities of Practice (CoPs) (Skyrme 2001).

- Learning Management System is the application platform covering the eLearning solution that provides functionalities for content management, delivery, learning management and other VE business services. It uses the Internet technologies to manage the interaction between users and learning resources. An e-Learning deployment starts with an assessment of current learning modes and new educational objectives for the trainees. These objectives should be in line with the VE business objectives.

- Learning Portal is a Web based, single point of access that serves as gateway to a variety of e-Learning resources for employees, partners and customers using various forms of CNs. It aggregates information based on VE communities with common needs/interests: Field, Manufacturing, Leadership Development, Partner Development, etc. Besides a navigational role, the portal can serve as launching point for business applications, content search, discussions and collaboration, workflow tools and other resources and services. The learning portal can be used also to reinforce CoPs: threaded discussions, online chat, news groups, online conferencing, instant messaging and personal web pages (Rosenberg, 2001).

\subsection{The Content Dimension}

It is very often that e-Learning initiatives get stuck with content issues such as availability and quality. The best strategy here is to create e-Learning content that relates directly to the learning objectives and is reusable in order to optimize efforts and resources - a shift from creating and delivering monolithic courses to finegrained content that can be reused in many contexts. A number of organizations that promote standards such as ADL (Advanced Distributed Learning) with its well known initiative SCORM (Sharable Content Object Reference Model), www.adlnet.org), IMS (Instructional Management System), www.imsproject.org), AICC (Airline Industry CBT Committee), www.aicc.org), ARIADNE (Advanced Distributed Learning), www.ariadne.unil.ch) and IEEE LTSC (IEEE Learning Technology Standards Committee, www.ltscl.org) play a major role by enabling 
interoperability, reusability and scalability. The content dimension comprises the following entities:

- Multimedia Streams are entities that pack the content with ingredients such as voice, data and video in order to enliven a course page and add visual variety to the learning experience. Because of constraints related to the real time specifics of these structures, their delivery quality is directly impacted by the quality of the infrastructure, specifically bandwidth and QoS. Streaming solutions available today come from Microsoft (WMT - Windows Media Technology), Real Networks (Real Video/Audio) and Apple (QT - Quick Time). ISMA (Internet Streaming Medial Alliance) is the organization whose purpose is to accelerate the adoption and deployment of open standards for streaming rich media content such as video, audio, and associated data, over Internet protocols.

- Reusable Information Objects (RIO) are self-contained chunks of information built around a single learning objective, as defined by (Clark, 1989): a concept, fact, procedure or principle. Each RIO is tagged with metadata that describes its characteristics, purpose and relationship with other objects. The term „reusable” is used to emphasize the advantage of authoring smaller pieces of learning that enable content repurposing. Thus, learning objects are created that form a useful database for content that may be recombined to fit specific needs.

- Reusable Learning Objects (RLO) are the lessons. As in the traditional lessons, RLO give learners the needed learning context, the knowledge and skills they need to perform towards a given objective and a method to assess mastery. According to (Cisco, 2001) a RLO can be created by combining an overview, summary, assessment and five to nine RIOs. A RLO is based on a single objective derived from a specific job task. Each RIO is built upon an objective that supports the RLO objective. The RLO approach has benefited the research and best practices found in (Merrill, 1983) and (Bloom, 1994) and has resulted in successful implementations (Clark, 2002) and (Rosenberg, 2001).

- E-Learning Curriculum joins together RLOs into a larger hierarchy depending on the author, business requirements and the packaging of the offering in the learning management system. The curriculum can also be expressed as an employee development roadmap or part of a performance support system that is customized to the learner. A sample structure of curriculum is as follows: Curriculum, Unit, Module, Lesson (RLO) and Section (RIO).

\subsection{The eServices Dimension}

This dimension includes the generic services available through the Web portal. There is still a large perception that learning is related to classroom teaching. That is why many people continue to see the web as an online replica of the classroom experience. However, online training is only a part of e-Learning. Access to the information is also essential for learning as instruction. From business performance to employee services, intranet-based knowledge management can create a communication and collaboration network that links every individual in the organization. The following components form the eServices dimension:

- Knowledge Management (KM) is the area that deals with the means to supply information that people can use and rely on. It supports the creation, archiving 
and sharing valued information, expertise and insight within and across communities of interest. Currently most businesses use Internet and the web and have abandoned the silo model of preserving information in favor of various forms of CNs (corporate intranets and extranets) that facilitate secured access to information for employees, partners, customers and suppliers. This trend reflects a knowledge management strategy - providing a common approach and a common architecture for managing information. KM differentiates from the information-laden Web sites by its focus on collaboration and community, allowing new ideas and insights to be shared in a more open environment, enabling trusted groups of professionals united by a common concern or purpose to reach new insights and enhance performance in a particular domain.

- Online Training - there is a strong opinion that simply providing information is an inefficient way to learn - that is why instruction is needed. An essential part of an e-Learning strategy, the Computer Based Training (CBT) has received the online ingredient in order to eliminate well known disappointments of CBT (unfit content, unauthentic learning, form-over-substance, etc.). Online training must provide simulation and interactivity in order to increase the authenticity and motivate the learner. The knowledge acquisition element of online training may come also from story telling. With primary learning on the $\mathrm{Web}$, the instructors are free to become true coaches and consultants to the trainees focusing more on facilitating the transfer of knowledge, converting themselves into e-moderators (Salmon, 2005).

- Authoring is an essential part of the E-learning system because only building an infrastructure and just placing a lot of content on a server is not enough. The reusable learning objects, content, sources and formats must be combined through authoring into sound instruction or information. The material is delivered through the learning portal via synchronous or asynchronous learning. Asynchronous delivery refers to programs that are independent of time (,prerecorded", as VoD). Synchronous programs are time dependent and take place in real time. The simplest forms of synchronous learning consist of classroom training but also some Web applications such as chat rooms, IP/TV live multicast, etc. While asynchronous programs require much deeper understanding of instructional design and are more costly to develop, synchronous programs also take into account important design considerations but focus more on delivery. Depending on the needs of the learner that result upon a competency assessment the right curriculum and other resources are delivered to the desktop. A new direction - „Edutainment" emerged from the combination of ,education" and „entertainment" that encompasses various aspects of pure information transfers as well as complex entertainment applications such as game-based learning environments (Encarnacao, 2004).

EBusiness refer the set of Internet enabled business tools for electronic commerce, workforce optimization, ERP, customer support, supply-chain automation and of course E-learning. We have included e-Business on the eServices dimension of the e-Learning cube because we see a trend for convergence of e-Learning and e-Business towards the knowledge commerce the ability to leverage an organization's intellectual assets to improve its competitive advantage. More and more e-Learning companies will convert 
themselves to Business-to-Business (B2B) or Business-to-Consumer (B2C) entities with e-Learning as a defining characteristic of their services offering. New models such as Business-to-Employee (B2E) and Employee-to-Employee (E2E) are placing e-Learning in the focus of the efforts to create more collaborative, knowledge-sharing work environments such as virtual communities. Knowledge products and services, Knowledge markets/distribution together with the e-commerce and the underlying Internet result in a new business, for marketing and sale of knowledge over the Internet, referred as K-Business.

\section{USABILITY OF THE MODEL - CASE STUDY}

Once the e-Learning cube was conceived it became essential to check upon its usability. The first opportunity was offered by a GSM company that provides mobile voice and data services on all territory of Romania. Operating from multiple locations across the country it also belongs to a global telecom organization thus presenting all characteristics of a VE. The company had recently acquired an eLearning application and was faced with the challenging task to successfully implement and get it fully adopted. By using the e-Learning cube model the HR and the training departments have succeeded to pass a very clear and consistent message about the implementation strategy to all the other departments within the organization and to deploy the first phase of e-Learning services. Among those, electronic training and assessment for work protection and accident prevention, as well as a GSM technologies curriculum for new employees. The first application was particularly appreciated because it took a lot of burden away from the HR department that was supposed to monitor the work protection activities in accordance with the law, stage periodic training sessions adapted to the specifics of the activity of more than 1000 employees scattered across the country as well as maintain accurate files. The lesson learned from this project was that the cube model was a valuable tool for positioning an e-Learning system in a collaborative environment mostly when it came to roles of various stakeholders, strategy and rollout planning. For example the IT department understood that they only needed to provide the intranet infrastructure and host the e-learning system (they were doing this anyway for many other applications across the $\mathrm{CE}$ ), the content generation was outsourced to a third party, and the functional departments (such as Operation and Maintenance, Network Planning, Sales, etc.) provided SMEs (Subject Matter Experts) for the validation of the content and the Training department started to convert the instructors into e-moderators. Eventually the HR department, traditionally composed of nontechnical personnel was able to manage a complex application in a technology driven virtual organization.

A second project in developed was proposed and is currently under evaluation with the EMeL (Experimental Mobile eLearning) initiative at IST Framework 6. 


\section{CLOSING REMARKS AND FURTHER WORK}

(Senge, 1990) defines the learning organizations as entities that continuously expand their capacity to create their future. In the KE one approach is to create an environment and a culture that encourages knowledge generation and sharing, supports learning by doing and ensures that learning is incorporated into future activities, decisions and initiatives of the company. Further efforts are focused towards ontology based E-Learning. This idea became obvious after understanding how the e-Learning cube was useful to the GSM operator. Ontology was defined (Gruber, 1993) as a formal, explicit specification of shared conceptualization. For the purpose of this paper "conceptualization" refers to the abstract model of the ELearning Cube. The term "Explicit” means that the type of concepts used and the constraints on their use are explicitly defined. „Formal” refers to the fact that the ontology should be machine understandable. There has been considerable effort put into the Meta languages to model VE processes and structures (Atanasiou, 2001). The term „Shared" reflects the trend of ontology as being able to capture consensual knowledge. Efforts are going both in the scientific direction as well as towards real world implementations of E-Learning solutions for Collaborative Networks.

\section{REFERENCES}

1. Stanescu, A.M., Dumitrache, I., Curaj, A., Caramihai, S.I. and Chircor, M. Supervisory Control and Data Acquisition for Virtual Enterprise, in Int. Prod. Res., 2002, Vol. 40, No 15, 3545-3559.

2. Hodgins, Wayne. Into the Future: A Vision Paper, www.learnativity.com, February 2000.

3. Clark, R. Putting Learning Standards into Practice, "ASTD E-Learning Handbook", McGraw Hill 2002.

4. Clark, R. Developing Technical Training: A Structured Approach, Perform Technology Press, 1989.

5. Cisco Systems. Reusable Learning Object Strategy, Version 4.0, November 2001.

6. Bloom, Benjamin S. and Krathwohl, David R. Taxonomy of Educational Objectives, Handbook 1: Cognitive Domain. Addison-Wesley Publishing Company, 1994.

7. Merrill, M.D. Component Display Theory, in Instructional Design Theories and Models. Edited by C.M. Reigeluth, Hillsdale, New Jersey, 1983.

8. Rosenberg, J. Mark. E-Learning, McGraw Hill 2001.

9. Senge, M. Peter. The Fifth Discipline: The Art and Practice of Learning Organization, New York, Doubleday, 1990.

10. Coulouris G., Dollimore J., Kindberg T. Distributed Systems, Concepts and Design, Addison Wesley 2001.

11. Skyrme, David J. Capitalizing on Knowledge: from e-business to k-business, Butterworth Heinemann 2001.

12. Encarnacao, Jose L. Edutainment - The colorful world of Computer - generated images, Europaischer Wirtschafts Verlag GmbH. 2004.

13. Gruber, T.R. „Towards Principles for Design of Ontologies used for Knowledge Sharing”, in Proceedings of International Workshop on Formal Ontology, Padova, Italy, 1993. Ed. N. Guarino.

14. Atanasiou, Maria. UEML State of the Art - Summary, IST-2001-37368, www.ueml.org, 2001.

15. E-learning: Implementing the 4-Tier Blended Leaming Model from IBM, White Paper, November 2001.

16. Dumke, Horst. Introduction to Content Delivery Protocols and Technologies, Cisco Systems 2003.

17. Camarinha-Matos, Luis, Afsarmanesh, Hamideh. Infrastructures for Virtual Enterprise, Kluver Academic Publishers, 1999.

18. PRO-VE 2004, IFIP Prodnet Working Conference for Virtual Enterprise, Zurich, Sept. 2004.

19. Garlasu, D., Stanescu, A.M. - A New Approach For E-Learning In Robotics, 14-Th International Workshop on Robotics in Alpe-Adria-Danube Region RAAD'05 Bucharest, Romania: May 2005. 